\title{
Political Reviews Editor's Note
}

Section editor's introductions are rare in The Contemporary Pacific, but they sometimes appear to mark transitions in intention or in fact. Since the journal's founding, the political reviews section has been separated along conventional colonial boundaries: "Micronesia" and "Polynesia" in the first issue of the year and "Melanesia" and the region as a whole in the second issue. Beginning with the current issue, I am hoping to begin to blur those conceptually problematic boundaries.

The current set of political reviews, while still divided along those lines, focuses on pressing themes affecting Pacific Island states. The CNMI, Cook Islands, Kiribati, and FSM reviews all highlight climate change and its impacts on those entities, while the reviews of Guam, French Polynesia, Rapa Nui, and Māori issues emphasize efforts at decolonization. In the next issue, reviews of "Melanesian" entities and the region will also emphasize political themes rather than colonial groupings.

The numerous moments of silence and absence in the political reviews section should also be noted, as not every political entity is accounted for. Some, such as Kiribati and Nauru, have been silent for almost two decades, while Hawaiian issues have not been reviewed since 2007. Yet their absence should not be a confirmation that they do not exist or are unimportant, and I am working to include them in future issues. The reality is that politics is a tricky business, and those who know it best in closeknit societies such as Oceania often walk a fine line between personal and public commitments.

I would like to close by thanking the TCP political reviews editors who preceded me, Terence Wesley-Smith and Scott Kroeker. They both worked tirelessly to include as many accounts as possible for the multitude of entities in Oceania, which would otherwise not be accessible. I also thank the review authors, past and present, for all their efforts in gathering the information and helping us make it useful for our readers. And I thank the readership for your patience as we move to bridge boundaries so that these reviews more clearly reflect the contemporary Pacific.

\section{DAVID W KUPFERMAN}

The Contemporary Pacific, Volume 27, Number I, 2 IO

(C) 2015 by University of Hawai' $i$ Press 